\title{
Seven Thousand Ways to Listen: Staying Close to What is Sacred
}

\begin{abstract}
Nepo, Mark. 2012. Seven Thousand Ways to Listen: Staying Close to What is Sacred. London \& New York: Simon \& Schuster Publication.
\end{abstract}

Reviewed by ROZY SAMEJA PATEL

The seven thousand ways to listen is sort of easy, conversational and probing book. It takes you to a journey within. In this book, the writer unearths some of the delicacies of feeling and emotions that in the process of living we are getting detached with. Those elements being our own inner world, something starts stirring in our mind with reference to different meditative poses and reflective aspects that the writer floats. It is a different take on sensibilities. It is highly spiritual amassing insights from world religions. Still mainly it manages to underline humanity as biggest.

I personally believe that silence is the best thing in this world. And listening comes near to it because it propels the silence. In noise also there is a silence. And silence is melodious! But in our limited strife for sound and silence and sound silence: we need an art of listening to unravel hidden symphony of things. That is equivalent to deciphering preordained patterns of destiny. Nevertheless, this book is about neither of those. It is on contrary a complete inside-out perspective from within to beyond. It would not be an exaggeration if I write that listening is first and foremost exercise for a linguist. Hence the book which I am going to review titled 'Seven Thousand Ways to Listen'. It is a chapter by chapter unrevealing of beautiful nuances of nature along 
with some very sacred but humane philosophies that can translate our mundane lives into some reverberating life!

Translation is an underplay of reading-perceivingbrainstorming-writing-rereading-repairing-sampling-and then again doing the same cycle of reading- and so on and so forth. This pattern is very stimulating to one's brain. Apart from being scholastic, this process is sensory- meaning it involves more than one basic sense. If it were just reading then eye and mind coordination would have been sufficed. But translation requires much more diligence than this. It requires doingundoing-redoing-undoing the redoing and then starting afresh. It is like a time series on a scale where numerical keep changing as per combinations and combinations keep varying because of numerical. In translation also words and expressions are like those numerical and combination in time series analysis. Each word to a linguist gives so many distinctive meanings and representations. It is like opening of a Pandora in infinity. That is why perhaps semantics and syntactic. In simple parlance, linguists or non-linguists, each one is strives for expressions. Now along with word and its infinite possibility of meanings, an additional twist to desired expression opens up a new wide array of altogether different probabilities.

So far everything is quite a pretty little jugglery of words in mind. A typical exercise for aptness and justification happens while one selects a word-expression combo out of the infinite probabilities. The real power play happens when those mere arrangements of words are uttered mentally or verbally and the sound of that utterance is getting slowly swirled in mind and in mouth. Very culinary type, isn't it? But aren't we trying to cook and concoct a new recipe out of old ingredients while we are translating? If you are smiling.... that takes some 
burden off my chest. Meaning something fruitful shall come from this recipe also. Pun intended!

Sorry for digressing but my point is that we should take the feel and flavor of the actual sound aloud of the write up as a final patch test. That means translation is not just verbal exercise but an audio as well. At this juncture I would like to float a theory that all those who speak well are essentially better listeners. It is universal theory in academia and my personal belief also. Good writers are most of the times excellent speakers and that again boils down to their innate or cultivated abilities of listening. And better listeners are unarguably best translators because listening gives them hang and pang of each language in which they work.

Ours is an era of paradoxes and oxymorons, of virtual reality and of real virtues, of parallel living and parallel world. By and large, it boils down to a theory and anti-theory. Maybe the contemplation gets much more clearly if theory of comparisons and theory of contrast are imbued. Same way this arena of especially last decade has been dominated by such cosmic paradoxes. Where in at one hand clone-engineering and at another actual humane insights are being increasingly sought. May be the technology has failed to transpire comfort levels mentally. Yes this era has been extremely uncomfortable one. Not physically of course if we discount some illintentioned violence on humanity.

If we go on probing further we come to realize that we have been really in easy in our minds. Not to mention that the amount of uneasiness has gradually increased. From the inception also there was a feeling of uneasiness which gave raise to doubts and then ultimately to discoveries. But those theories of evolution have long been done and dusted. What I am attempting to put forward is realization and acceptance of 
that age old feeling of uneasiness that has been increasingly done in this decade.

The writer, Mark Nepo is a master craftsman of unearthing that uneasiness beneath and tendering it an ethereal beyond. He captures those illusive feelings so correctly that manifestation from reader's point of view becomes as surreal as a fantasy and as hard hitting as a fact. That is why perhaps his first and an award winning book is called 'The Awakening'!

It is a refreshing take on otherwise mystic and spiritual exposure that humanity have had so far. It takes you into depth of being and onto soaring heights of vision at one go. Sometimes I tell my students that they do not have to be serious for learning or teaching serious subjects. Probably Mark Nepo was there in my class (needless to say it's a PJ!) because he does the same. At the cost of being flippant, I want to say that sounding frivolous is not too bad provided that it retains the write-up in lighter mode which is much more communicative. Of course, Mark Nepo is an authority to impart very intellectual broodings with feather light touch.

Another break-through that this concept book has done is it has connected to reader at some inexplicable level. Moreover some younger generations have got instant connect to this book. Otherwise concepts as such are written most of the times while keeping a mature or sometimes over-mature target audience in mind. Quite contrary to that, ' 7000 ways to listen' radically gels through a mass of all ages and all walks of life. And if this much was not enough, let me tell you that this book is one of those rare books that has after-life. Yes for sure! It is a book which stays by the bed-side of almost every second reader propelling one to re-read and rediscovers the 
latent wonders of universal designs. It propels the likes of scholars, psychologists, humanitarians to practise some of the concepts of the book to add value to life and life to values. I won't mind admitting that it gives a 'Deja-vu' kind of feeling in the reader. That probably gives it a repeat value. It is, on and on, a deeply magnetic book written on some very uneasy ephemeral experiences. But unflinchingly makes those, by the end, much more easily acceptable!

The book is originally panned out in 3 sections and 38 sub-sections. Those 3 sections are called: I. The Work of Being II. The Work of Being Human, III. The Work of Love. 